\title{
Accuracy of common stem volume formulae using terrestrial photogrammetric point clouds: a case study with savanna trees in Benin
}

\author{
Hospice A. Akpo ${ }^{1}$. Gilbert Atindogbé ${ }^{1}$. \\ Maxwell C. Obiakara $^{2} \cdot$ Arios B. Adjinanoukon $^{1}$. \\ Madaï Gbedolo $^{1} \cdot$ Noël H. Fonton ${ }^{1}$
}

Received: 4 November 2020 / Accepted: 16 February 2021 / Published online: 20 April 2021

(C) The Author(s) 2021

\begin{abstract}
Recent applications of digital photogrammetry in forestry have highlighted its utility as a viable mensuration technique. However, in tropical regions little research has been done on the accuracy of this approach for stem volume calculation. In this study, the performance of Structure from Motion photogrammetry for estimating individual tree stem volume in relation to traditional approaches was evaluated. We selected 30 trees from five savanna species growing at the periphery of the W National Park in northern Benin and measured their circumferences at different heights using traditional tape and clinometer. Stem volumes of sample trees were estimated from the measured circumferences using nine volumetric formulae for solids of revolution, including cylinder, cone, paraboloid, neiloid and their respective fustrums. Each tree was photographed and stem volume determined using a taper function derived from tri-dimensional stem models. This reference volume was compared with the results of formulaic estimations.
\end{abstract}

Project funding: The work was supported by the International Foundation for Science (Grant No: I-1-D-60661).

The online version is available at http://www.springerlink.com.

Corresponding editor: Tao Xu.

Supplementary Information The online version contains supplementary material available at https://doi.org/10.1007/ s11676-021-01333-9.

Hospice A. Akpo

hosakpo@yahoo.fr

1 Laboratoire d'Études et de Recherche en Statistiques et Biométrie Appliquée, FSA, Université D’Abomey-Calavi, 01 BP 526, Cotonou, Bénin

2 Ecology Unity, Department of Botany, University of Ibadan, Ibadan 20084, Nigeria
Tree stem profiles were further decomposed into different portions, approximately corresponding to the stump, butt $\log$ s and $\operatorname{logs}$, and the suitability of each solid of revolution was assessed for simulating the resulting shapes. Stem volumes calculated using the fustrums of paraboloid and neiloid formulae were the closest to reference volumes with a bias and root mean square error of $8.0 \%$ and $24.4 \%$, respectively. Stems closely resembled fustrums of a paraboloid and a neiloid. Individual stem portions assumed different solids as follows: fustrums of paraboloid and neiloid were more prevalent from the stump to breast height, while a paraboloid closely matched stem shapes beyond this point. Therefore, a more accurate stem volumetric estimate was attained when stems were considered as a composite of at least three geometric solids.

Keywords Structure from motion photogrammetry . Point cloud data $\cdot$ Stem volume $\cdot$ Savanna species $\cdot$ Benin

\section{Introduction}

Accurate estimates of the volume of tree stems is essential for characterizing forest stands and managing forest resources (West 2015). Stem volume is also the basis for commercial timber transactions because it is strongly correlated with the carbon storage potential of individual trees (Kankare et al. 2013; Yu et al. 2013). However, obtaining accurate stem volumes of standing trees is particularly difficult and time-consuming, given that stems are not perfect geometric shapes. Hence, this metric can be easily overestimated, especially for trees with irregularly shaped stems (Dean 2003; Bauwens et al. 2017). Several factors have been attributed to inaccurate stem volume estimation, mainly 
measurement errors and the wrong choice of allometric equations (Dean 2003; West 2015).

Of the several approaches to determine stem volumes, the most widely used are based on formulae of geometric solids such as cylinder, paraboloid, neiloid and their fustrums. Other less common approaches include water displacement, graphical and integration methods (Kershaw et al. 2016). The most common formulae for measuring stem volume are based on the product of the length of a stem segment and the weighted average of its cross-sectional area (West 2015). These formulae vary depending on the number of cross-sections considered, their relative position along the stem segment and the weight assigned to each cross-section. For example, with Huber's formula, a cross-sectional area is taken only at the middle of the segment. Smalian's formula uses two cross-sectional areas, at the bottom and top of the stem, and assigns equal weight to both measurements. Newton's formula, on the other hand, differs from Smalian's by an additional cross-sectional area measured at the middle of the stem segment with a fourfold weight assigned to it.

The choice of one of these common formulae depends mostly on practical considerations, such as the ability to measure more circumferences or diameters on a given stem segment. Because it involves three measurements on a stem section, Newton's formula is generally more accurate (Kershaw et al. 2016). Moreover, it takes into account the wide range of shapes (paraboloid, neiloid, cylinder and cone) commonly assumed by tree stems. However, Smalian's approach is often preferred because mid-sectional measurements are not always practical in the field (West 2015).

Exact stem volume determination is conventionally done using the water displacement approach, also known as xylometry, which involves the immersion of logs in a known amount of water and measuring the resulting increase in volume. Although this technique is quite accurate, it is very restrictive in its application (Özçelik et al. 2008; Akossou et al. 2013). For example, considerable logistical constraints must be overcome to make useful quantities of water available in typical field settings. Moreover, xylometry is destructive and may not always justify overestimations often associated with the abovementioned methods and more recent alternatives such as the centroid and centre of gravity approaches (Özçelik et al. 2008). However, toward overcoming the shortfalls of xylometry, many studies have explored the utility of point cloud data derived from terrestrial laser scanning, TLS (Kankare et al. 2013; Yu et al. 2013; Liang et al. 2016; Saarinen et al. 2017; Hyyppä et al. 2020) and Structure from Motion (SfM) photogrammetry (Morgenroth and Gómez 2014; Miller et al. 2015; Koeser et al. 2016; Mulverhill et al. 2019) for accurate stem volume determination.

In many cases, the accuracy of terrestrial image-based point cloud data has been shown to be marginally lower than that of TLS point clouds (Liang et al. 2014, 2015; Panagiotidis et al. 2016; Huang et al. 2018; Piermattei et al. 2019). In an extensive comparison involving several image acquisition scenarios for plot-based mensuration, Liang et al. (2015) found a small mean difference (using tape measurements as a reference) between laser and imagederived breast height diameter of Scots pines, in the order of $0.23-0.28 \mathrm{~cm}$ and -1.34 to $3.07 \mathrm{~cm}$, respectively. Another comparison between these methods (Piermattei et al. 2019) across heterogeneous forest plots produced similar breast height diameter errors ranging from 0.87 to $3.75 \mathrm{~cm}$ (TLS) and 1.21 to $5.07 \mathrm{~cm}$ (SfM photogrammetry). The recent use of highly mobile TLS devices has eliminated the logistical constraints hitherto associated with this technique in remote and hard-to-access locations (Hyyppä et al. 2020). However, costs still remain a major limitation as opposed to imagebased approaches (Huang et al. 2018; Iglhaut et al. 2019).

With recent developments in the fields of computer vision and photogrammetry, smart phone and digital single-lens reflex cameras have been increasingly used as low-cost devices for creating tri-dimensional models. Promising results have been reported from the application of SfM photogrammetry in forestry at scales ranging from forest plots (Liu et al. 2018; Mokroš et al. 2018; Piermattei et al. 2019) to individual trees (Morgenroth and Gómez 2014; Miller et al. 2015; Bauwens et al. 2017; Huang et al. 2018; Mulverhill et al. 2019; Roberts et al. 2019; Marzulli et al. 2020). However, many studies exploiting photogrammetric point cloud data seem to focus more on linear metrics, (i.e., breast height diameter and tree height), than volumetric metrics. The first direct comparison between actual and point cloud-derived data of tree volume was carried out by Miller et al. (2015). They showed that photogrammetrically derived stem volumes of potted trees were reasonably close to their true volume - determined xylometrically - with a root mean square error and mean difference (bias) of $12.3 \%$ and $-8.2 \%$, respectively. Mulverhill et al. (2019) also found no significant difference between stem volumes obtained from point cloud data and volumetric estimates derived from sectional measured stem diameters of felled trees.

In the context of precision forestry, the present study examines the application of ground-based SfM photogrammetry for tri-dimensional tree structure. The strength of this study was the ability to capture the full height of the mostly short-stemmed savanna species from the ground, as opposed to some recent studies that highlighted the limitations of this method, especially for excurrent trees, ones with a single leader (Mulverhill et al. 2019; Marzulli et al. 2020). Thus, our specific objectives were to compare stem volume estimations based on common geometric solids using terrestrial photogrammetric point clouds as a reference and to examine the suitability of each solid for simulating different stem shapes in relation to height. 


\section{Materials and methods}

\section{Study site}

The study site, in the buffer zone of the W National Park $\left(11^{\circ} 26^{\prime}\right.$ to $12^{\circ} 25^{\prime} \mathrm{N} ; 2^{\circ} 48^{\prime}$ to $3^{\circ} 05^{\prime} \mathrm{E}$; $164 \mathrm{~m}$ a.s.l.) is in northern Benin (Fig. 1). It has a strong seasonal tropical climate and is located within the West African Sudanian Savanna which stretches from Senegal to Nigeria. The mean temperature in this area is $40^{\circ} \mathrm{C}$, and rainfall varies between 600 and $700 \mathrm{~mm} \mathrm{a}^{-1}$.

\section{Sampling and stem volume estimation using traditional techniques}

Our sample was based on five of the most dominant tree species in the study area selected from the National Forest Inventory database (Projet 2009): Anogeissus leiocarpa (DC.) Guill. \& Perr., Bombax costatum Pellegr. \& Vuillet, Sclerocarya birrea (A. Rich.) Hochst., Terminalia laxiflora Engl. and Vitellaria paradoxa Gaertn. f.. For each species, six trees were sampled in each of the following DBH classes $(\mathrm{cm}): 10-20,>20-30,>30-40,>40-50,>5$ $0-60$ and $>60$. Measurements were made using traditional tools (diameter tape and clinometers) and are presented in Table S1.

Stem circumferences were measured at $0.10 \mathrm{~m}, 0.50 \mathrm{~m}$, $1.30 \mathrm{~m}$ and $1.50 \mathrm{~m}$ above ground level. Additional measurements were taken at $1-\mathrm{m}$ intervals from $1.50 \mathrm{~m}$ up to bole height (i.e., at the top of the stem below the first branch) using a ladder in few cases. Prior to measuring, all heights were marked by a thin, horizontal red line drawn around the trunk. Stem segments defined by two consecutive markings formed the basis for volumetric estimations. Volume of stem segments was estimated using the formulae in Table 1 (Kershaw et al. 2016), and stem volume was obtained by summing individual segment volumes (West 2015). Values computed from each species are in Table $\mathrm{S} 2$.

\section{Image acquisition and photogrammetric point cloud generation}

Tri-dimensional models of the sample trees were built using SfM (Morgenroth and Gómez 2014; Miller et al. 2015). Image acquisition was done on a circular path with a $2-\mathrm{m}$ radius around the stem (Akpo et al. 2020). The distance between two consecutive camera positions was defined by an angle of $15^{\circ}$ on the circular path (Fig. 2). These positions were marked by stakes driven into the ground. A series of

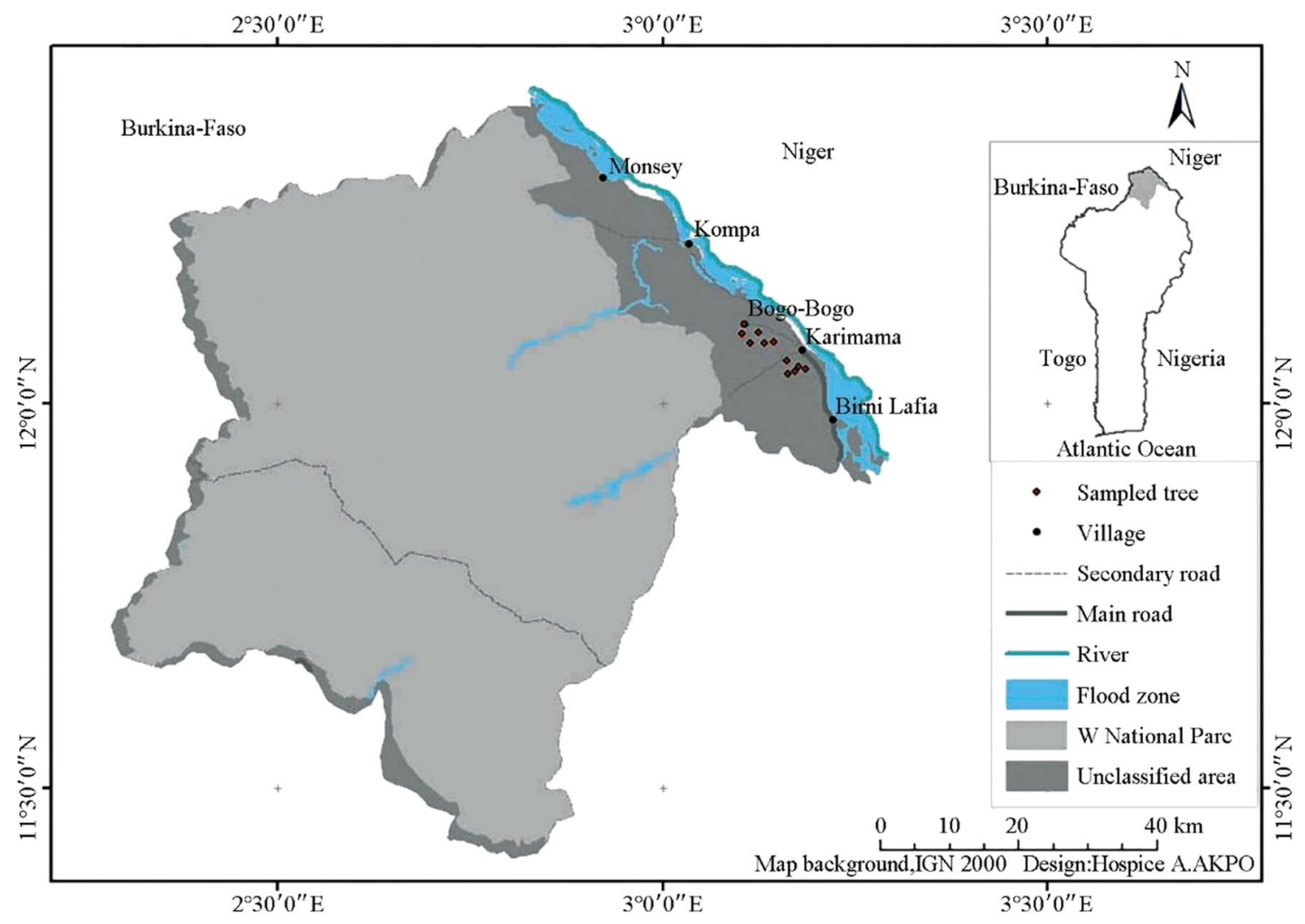

Fig. 1 Map of study area 
highly overlapping images were captured at a given position from the base of the stem to the top before moving to the next one. All images were taken with a Canon $77 \mathrm{D}$ camera equipped with a Canon EF $50 \mathrm{~mm}$ f/1.8 STM lens. For optimal results, the camera was set to its maximum resolution $(6000 \times 4000$ pixels $)$ and held parallel to the stem in portrait orientation. The aperture priority mode (f/3.2) and lowest ISO value (100) were maintained during image acquisition to obtain clear and high quality images. Before photographing each tree, a $1.5 \mathrm{~m}$ ruler was vertically pinned to the stem for subsequent scaling.

Although stem circumference can be estimated on manually delineated point-based stem contours in a geographical information system (GIS) environment (Bauwens et al. 2017; Akpo et al. 2020), in this study, we automated stem crosssection delineation for volume estimation in the $\mathrm{R}$ programming language (R Core Team 2017). Scaled tri-dimensional tree models were built using Agisoft PhotoScan Pro. 0.9.1 (Agisoft LCC, St. Petersburg, Russia). The workflow in this program consists of three main steps: (1) loading images, (2) aligning images and (3) building a dense point cloud. PhotoScan users can control outputs at each step via a suite of settings depending on the desired accuracy and computer processing power (Fang and Strimbu 2017; Mulverhill et al. 2019). The steps and settings used in generating tree models in this study are shown in Fig. 3, in line with Akpo et al.
Table 1 Common formulae for stem segment volume estimation

Fig. 2 Image acquisition schema

Fig. 3 Image processing workflow of PhotoScan settings used in this study

\begin{tabular}{|c|c|c|c|}
\hline Geometric solid & Volume equation & & Equation no \\
\hline Cone & $\frac{L}{12 \pi} C_{\mathrm{T}}^{2}$ & & Equation 1 \\
\hline Cylinder & $\frac{L}{4 \pi} C_{\mathrm{T}}^{2}$ & & Equation 2 \\
\hline Paraboloid & $\frac{L}{8 \pi} C_{\mathrm{T}}^{2}$ & & Equation 3 \\
\hline Paracone & $\frac{L}{10 \pi} C_{\mathrm{T}}^{2}$ & & Equation 4 \\
\hline Neiloid & $\frac{L}{16 \pi} C_{\mathrm{T}}^{2}$ & & Equation 5 \\
\hline Paraboloid fustrum & $\frac{L}{4 \pi} C_{\mathrm{M}}^{2}$ & (Huber's formula) & Equation 6 \\
\hline Paraboloid fustrum & $\frac{L}{8 \pi}\left(C_{\mathrm{T}}^{2}+C_{\mathrm{B}}^{2}\right)$ & (Smalian's formula) & Equation 7 \\
\hline $\begin{array}{l}\text { Neiloid, cone or } \\
\text { paraboloid fustrum }\end{array}$ & $\frac{L}{24 \pi}\left(C_{\mathrm{T}}^{2}+4 C_{\mathrm{M}}^{2}+C_{\mathrm{B}}^{2}\right)$ & (Newton's formula) & Equation 8 \\
\hline Neiloid fustrum & $\frac{L}{16 \pi}\left(C_{\mathrm{T}}^{2}+\sqrt[3]{C_{\mathrm{T}}^{4}+C_{\mathrm{B}}^{2}}+\sqrt[3]{C_{\mathrm{T}}^{2}+C_{\mathrm{B}}^{4}}+C_{\mathrm{B}}^{2}\right)$ & (Huber's formula) & Equation 9 \\
\hline
\end{tabular}

$\mathrm{L}$ is length of a stem segment; $C_{\mathrm{T}}, C_{\mathrm{M}}$ and $C_{\mathrm{B}}$ are circumference at top, middle and bottom
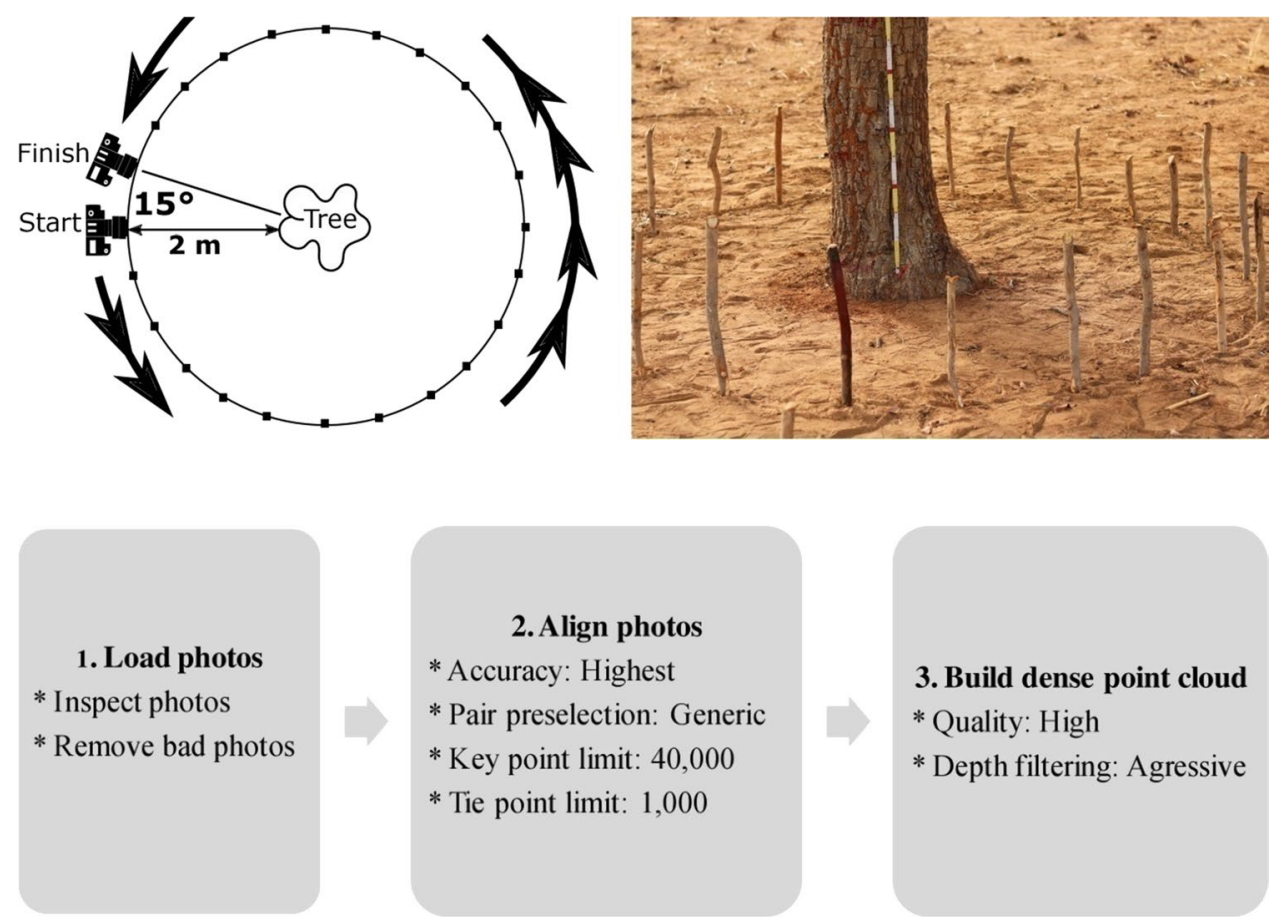

2. Align photos

* Accuracy: Highest

* Pair preselection: Generic

* Key point limit: 40,000

* Tie point limit: 1,000
3. Build dense point cloud

* Quality: High

* Depth filtering: Agressive 
(2020). Further processing was based on the spatial coordinates of points in the resulting tri-dimensional models.

\section{Stem volume determination using point cloud data}

Spatial coordinates of point clouds were imported in the $\mathrm{R}$ programming environment, and horizontal sections (hereafter referred to as slices) of varying thicknesses $(0.1 \mathrm{~cm}$, $1 \mathrm{~cm}, 50 \mathrm{~cm}$, and $100 \mathrm{~cm}$ ) were created from the base up to bole height. In most cases, slices had points well outside stem contours. To reduce errors in cross-section delineation, these outliers were detected and removed using the lofactor() function of the $D M w R$ package (Torgo and Torgo 2013). Slice cross-sectional area was computed based on the Cartesian coordinates of each point of the slice. The centroid of each slice was determined and taken as the origin of a new Cartesian coordinate system in which coordinates of all points of a slice were derived. Then, distances and azimuths of all points were determined in relation to the centroid. The azimuth of a point $\left(X_{1}, Y_{1}\right)$ was given by:

$\theta=(180 / \pi) \arctan 2\left(X_{1}, Y_{1}\right)$

Points in each slice were then ordered following azimuths and slice cross-sectional area $(S)$ was determined using the formula of Rondeux (1999):

$S=\sum_{i=1}^{n} X_{i}\left(Y_{i+1}-Y_{i-1}\right)$

where $X_{i}$ and $Y_{i}$ are the coordinates of point $i$ in the slice and $n$ the number of points in the slice.

A stem profile function was developed by testing several functions (e.g., exponential, logarithmic, linear and polynomial) to identify the one that best described how slice crosssectional area varied along the stem. Generally, data from all trees were best fit by an exponential function. The volume of a slice was then expressed as the product of this function, $S(x)$ and slice thickness $d x$. Stem volume was obtained by summing the volumes of all slices from the base $(0.1 \mathrm{~m})$ up to stem height (h) as follows:

$V=\int_{0.1}^{h} S(x) d x$

\section{Data analysis}

Stem volumes estimated using the nine formulae were reported in terms of arithmetic mean, standard error of the mean, minimum and maximum. The accuracy of the volume was evaluated using the relative bias $(B)$ and root mean square error (RMSE) as defined in the equations below:
$B=100\left[\frac{1}{n} \sum_{i=1}^{n}\left(\frac{V_{C(i)}-V_{R e f(i)}}{V_{R e f(i)}}\right)\right]$

$R M S E=100\left[\sqrt{\frac{1}{n} \sum_{i=1}^{n}\left(\frac{V_{C(i)}-V_{R e f(i)}}{V_{R e f(i)}}\right)^{2}}\right]$

where $V \mathrm{c}_{(i)}$ is stem volume estimated in the field using a tape for tree $i, V_{\operatorname{Ref}(i)}$ is volume obtained using the reference method, and $n$ the total number of trees.

\section{Results}

\section{Comparison of volume formulae}

Stem volumes estimated from field measurements were highest for V. paradoxa and lowest for A. leiocarpa. Regardless of species, the neiloid formula produced the lowest volumes whereas cylinder estimates were the highest (Table S2). Mean bias and RMSE values between field and photogrammetric estimates of stem volume based on increasing stem slice thicknesses are presented in Table 2. The negative bias obtained from the cone, neiloid, paraboloid and paracone formulae suggests that these solids underestimate stem volume. Conversely, results based on the cylinder, paraboloid fustrum (Huber's and Smalian's formulae), and neiloid/cone fustrums (Newton's formula), and neiloid (Eq. 5) indicated that these geometrical shapes tend to overestimate stem volume. Stem segment volume from fustrums of neiloid and Huber's formulae produced the lowest bias (8.0\%) and RMSE (20.4\%) in relation to stem volumes computed by integrating surface area for $1 \mathrm{~mm}$ and $1 \mathrm{~cm}$ slices. However, a twofold increase in bias was obtained with $50 \mathrm{~cm}$ slices (Table 2).

\section{Variation of segment stem volume in relation to height}

The variation in bias and RMSE in relation to stem height is shown in Fig. 4. The change in bias was similar across the length of the stem for volumes calculated using neiloid fustrum, Huber's, Smalian's and Newton's formulae. This pattern suggests that stems can be partitioned into the following portions: (1) butt $\operatorname{logs}(0.3 \mathrm{~m} \leq$ height $\leq 1 \mathrm{~m})$ for which bias values ranged from 17.0 to $18.5 \%$, (2) middle $\operatorname{logs}(1 \mathrm{~m}<$ height $\leq 2.5 \mathrm{~m})$ with bias values from 22.7 to $28.6 \%$, and (3) top logs $2.5 \mathrm{~m}<$ height $\leq 4 \mathrm{~m}$ with a bias value of $19.4 \%$. In contrast, the lowest $R M S E$ values were obtained only for butt logs using both fustrums of paraboloid and neiloid formulae. Above breast height $(1.3 \mathrm{~m})$, the stems of the study species assumed a paraboloid form. These results are summarized in Table S3. 
Table 2 Comparison of stem volume between traditional and point cloud- based data in relation to different geometric solids

\begin{tabular}{|c|c|c|c|c|c|c|c|c|c|c|}
\hline \multirow[t]{2}{*}{ Statistic } & \multicolumn{10}{|c|}{ Geometric solid } \\
\hline & $h$ & Cone & Cylinder & $\begin{array}{l}\text { Paraboloid } \\
\text { fustrum } \\
\text { (Huber) }\end{array}$ & Neiloid & $\begin{array}{l}\text { Neiloid/cone/ } \\
\text { paraboloid fustrum } \\
\text { (Newton) }\end{array}$ & Paraboloid & Paracone & $\begin{array}{l}\text { Paraboloid } \\
\text { fustrum (Sma- } \\
\text { lian) }\end{array}$ & Neiloid fustrum \\
\hline \multirow[t]{4}{*}{ Biais (\%) } & 0.1 & -61.2 & 15.3 & 8.0 & -71.2 & 8.2 & -42.1 & -53.7 & 8.6 & 8.0 \\
\hline & 1 & -61.2 & 15.4 & 8.1 & -71.2 & 8.2 & -42.1 & -53.7 & 8.6 & 8.1 \\
\hline & 50 & -57.9 & 25 & 17.2 & -68.8 & 17.4 & -37.2 & -49.8 & 17.9 & 17.3 \\
\hline & 100 & -53.1 & 39.3 & 31.1 & -65.2 & 31.3 & -30.1 & -44 & 31.8 & 31.1 \\
\hline \multirow[t]{4}{*}{$\operatorname{RMSE}(\%)$} & 0.1 & 61.5 & 23.8 & 20.4 & 71.3 & 20.6 & 43.1 & 54.2 & 20.7 & 20.4 \\
\hline & 1 & 61.5 & 24 & 20.6 & 71.3 & 20.7 & 43.1 & 54.2 & 20.8 & 20.6 \\
\hline & 50 & 58.6 & 37 & 33.0 & 69.1 & 33.2 & 39.7 & 51 & 33.5 & 33 \\
\hline & 100 & 54.5 & 53.6 & 49.9 & 65.8 & 50.2 & 35.2 & 46.5 & 50.6 & 49.9 \\
\hline
\end{tabular}

Comparison is between stem volumes estimated from tape-measured circumferences using the nine equations in Table 2 and stem volume computed by integrating individual volumes of stem slices of varying thickness $(h \mathrm{in} \mathrm{cm})$. The lowest values are presented in bold

Fig. 4 Accuracy of stem volume computed from photogrammetric point clouds data using different geometric solids in relation to stem height

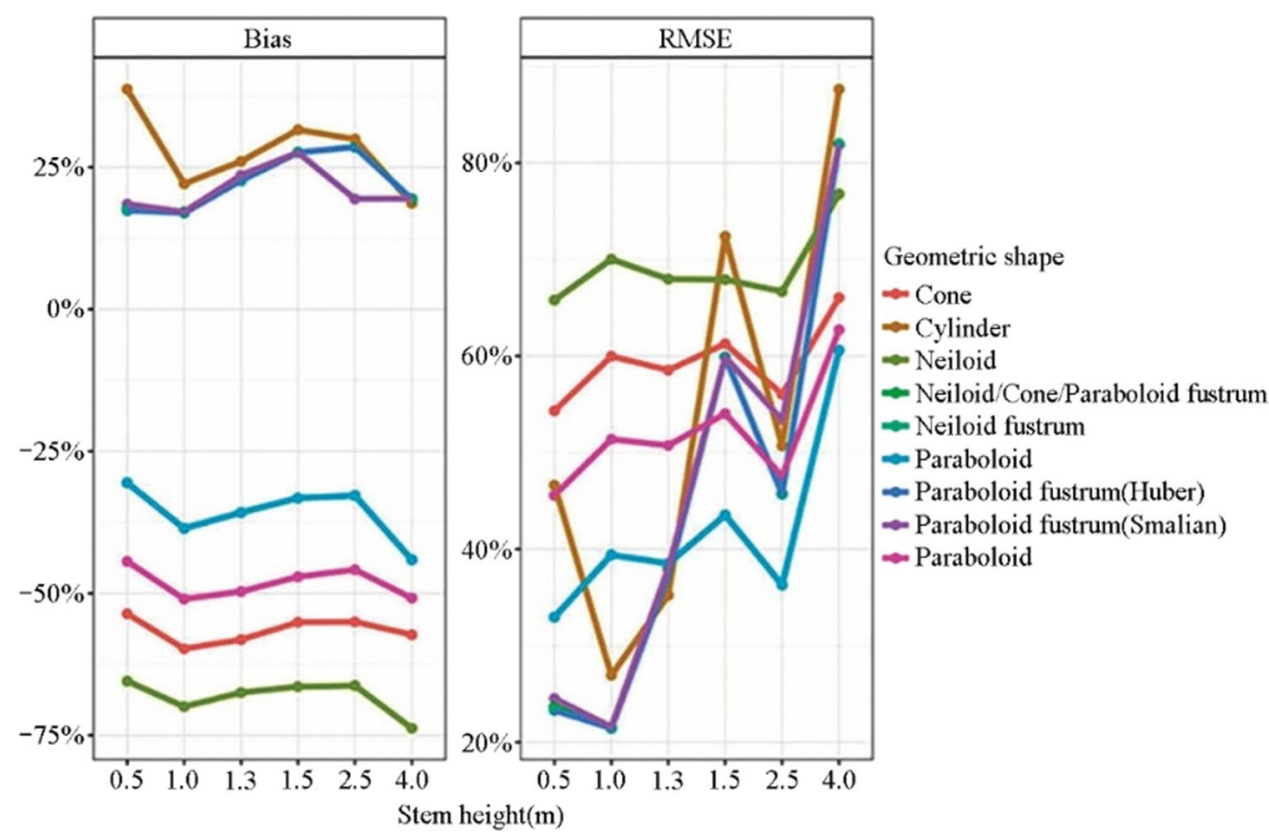

\section{Discussion}

A number of factors, including high tree density, occlusions and poor light conditions can limit the photogrammetric data acquisition process in a typical forest. These factors, combined with the low resolution of ground-operated passive sensors explain the inability to efficiently reconstruct the tridimensional structure of trees or forest plots for subsequent volume estimations. In this study, we assessed the accuracy of formulae for nine geometric solids for estimating stem volumes of five savanna species using terrestrial photogrammetry as a reference method. The volume of inherently irregular solids such as tree stems is most accurately measured by xylometry (Özçelik et al. 2008; Akossou et al. 2013).
Because this approach was not practical for this study, we took advantage of terrestrial photogrammetric point cloud data to derive the stem volume of standing trees. The use of this technique as a reference can be justified by its accuracy, close to but a little lower than that of the more popular and costly laser scanning technologies (Panagiotidis et al. 2016; Huang et al. 2018). In addition, Miller et al. (2015) tested the suitability of this method for stem volume estimation, whereas Koeser et al. (2016) underscored its utility for estimating the volume of geometrically complex shapes assumed by tree root systems.

Our accuracy assessment showed that four out of the nine geometric shapes tested were useful for determining stem volume. The most accurate of the four were the fustrums 
of paraboloid (Huber's formula) and neiloid with a similar performance. Calculation of stem volume using a fustrum of neiloid requires the cross-sectional areas at the base and upper end of a stem segments whereas Huber's formula uses only the middle cross-sectional area. Thus, based on the principle of parsimony, Huber's formula can be considered as the most accurate approach for estimating stem volume of the selected savanna trees. This finding is in line with the results of previous studies (Filho et al. 2000; Akossou et al. 2013). Using xylometry, these authors showed that Huber's formula produced the most accurate log volume for Tectona grandis L.f. and Pinus elliottii Engelm., respectively. Therefore, as expected for most deliquescent species, the general shape of the stem of the five most abundant ones in the Sudanian Savanna closely resemble fustrums of paraboloid and neiloid rather than their non-truncated equivalents (Kershaw et al. 2016). Our results also indicated that Newton's formula is less prone to bias, thereby confirming its versatility for most log shapes (West 2015).

The important increase in bias and RMSE obtained between stem volumes derived from integral calculus of increasing slice/sections and their formulaically calculated equivalents provide more insight into the effect of log length on stem volume accuracy. This agrees with earlier reports by Filho et al. (2000) and Akossou et al. (2013) in which increasing log lengths of $P$. elliottii and $T$. grandis, respectively, were compared with volumes determined by water displacement. Miller et al. (2015) reported a bias and RMSE of $-8.2 \%$ and $12.3 \%$, respectively, for volumetric estimates of the stems of small potted plants. Stem volumes based on tape measurements using Huber's formula showed a bias comparable to that of Miller et al. (2015). Contrary to their result, most formulaic values in this study had a positive bias, suggesting an overestimation of volume. To the best of our knowledge, the study by Miller et al. (2015) is the only one to directly compare photogrammetric volume to true stem volume determined by water displacement. However, the physical context of their study and their use of small potted plants in a controlled environment is different from that of the present study, which is based on trees in their natural habitat.

Mulverhill et al. (2019) found no significant differences between point cloud-derived stem volumes of standing trees and volumes estimated on felled trees. They reported an accuracy $(\mathrm{RMSE}=18.1 \%)$ comparable with that of this study. It is noteworthy that some strengths and weaknesses of the tested method were evident in recent studies in natural forests (Mulverhill et al. 2019; Marzulli et al. 2020). Because of the inability of ground-based photographs to capture the full height of stems, these authors resorted to a database of taper curves to generate metrics from the non-captured upper stem portions (above $5 \mathrm{~m}$ ). Thus, more difficulties may be expected in volumetric estimation of stems of excurrent trees using photogrammetric point clouds as opposed to the mostly deliquescent savanna trees in this study. Moreso, the maximum stem height $(4.5 \mathrm{~m})$ was measured on $B$. costatum.

Our results show that stem portions assume different geometrical shapes in relation to height. Tree stems in this study were morphologically complex, and perhaps better described as a "stack" of geometrical solids, with some solids more prevalent at a given height than others (Kershaw et al. 2016). The stem could be easily partitioned into three major portions using breast height as the reference level. Stem portions below breast height assumed the shape of fustrums of paraboloid and neiloid, whereas those above closely resembled a paraboloid. These shapes are in consonance with the theory of tree stem forms (Burkhart and Tomé 2012; Kershaw et al. 2016).

\section{Conclusions}

This study identified the best geometrical solid for determining stem volume. Terrestrial photogrammetry is welladapted for savanna trees because of their short heights. The results show that Huber's formula was the best approach for estimating stem volumes of tropical savanna species in West Africa. We also showed that stem section length has an effect on the tested volume formulae because greater log segments led to greater errors. The stem of the study species was a composite of three classical geometrical shapes. Our results should provide foresters with more appropriate options for estimating the volume of certain natural species.

Open Access This article is licensed under a Creative Commons Attribution 4.0 International License, which permits use, sharing, adaptation, distribution and reproduction in any medium or format, as long as you give appropriate credit to the original author(s) and the source, provide a link to the Creative Commons licence, and indicate if changes were made. The images or other third party material in this article are included in the article's Creative Commons licence, unless indicated otherwise in a credit line to the material. If material is not included in the article's Creative Commons licence and your intended use is not permitted by statutory regulation or exceeds the permitted use, you will need to obtain permission directly from the copyright holder. To view a copy of this licence, visit http://creativecommons.org/licenses/by/4.0/.

\section{References}

Akossou AY, Arzouma S, Attakpa EY, Fonton NH, Kokou K (2013) Scaling of teak (Tectona grandis) logs by the xylometer technique: accuracy of volume equations and influence of the log length. Diversity 5(1):99-113. https://doi.org/10.3390/d5010099

Akpo HA, Atindogbé G, Obiakara MC, Adjinanoukon AB, Gbedolo M, Lejeune P, Fonton NH (2020) Image data acquisition for estimating individual trees metrics: closer is better. Forests 11(1):121. https://doi.org/10.3390/f11010121 
Bauwens S, Fayolle A, Gourlet-Fleury S, Ndjele LM, Mengal C, Lejeune P (2017) Terrestrial photogrammetry: a non-destructive method for modelling irregularly shaped tropical tree trunks. Methods Ecol Evol 8(4):460-471. https://doi.org/10.1111/2041210X.12670

Burkhart HE, Tomé M (2012) Modeling forest trees and stands. Springer, $\mathrm{p} 58$

Dean C (2003) Calculation of wood volume and stem taper using terrestrial single-image close-range photogrammetry and contemporary software tools. Silva Fenn 37(3):359-380. https://doi.org/ $10.14214 /$ sf.495

Fang R, Strimbu BM (2017) Stem measurements and taper modelling using photogrammetric point clouds. Remote Sens-Basel 9(7):716. https://doi.org/10.3390/rs9070716

Filho AF, Machado SA, Carneiro MRA (2000) Testing accuracy of log volume calculation procedures against water displacement techniques (xylometer). Can J Forest Res 30(6):990-997. https:// doi.org/10.1139/x00-006

Huang HY, Zhang H, Chen CC, Tang LY (2018) Three-dimensional digitization of the arid land plant Haloxylon ammodendron using a consumer-grade camera. Ecol Evol 8(11):5891-5899. https:// doi.org/10.1002/ece3.4126

Hyyppä E, Kukko A, Kaijaluoto R, White JC, Wulder MA, Pyörälä J, Liang XL, Yu XW, Wang YS, Kaartinen H, Virtanen JP, Hyyppä J (2020) Accurate derivation of stem curve and volume using backpack mobile laser scanning. ISPRS J Photogramm 161:246-262. https://doi.org/10.1016/j.isprsjprs.2020.01.018

Iglhaut J, Cabo C, Puliti S, Piermattei L, O'Connor J, Rosette J (2019) Structure from motion photogrammetry in forestry: a review. Curr For Rep 5(3):155-168. https://doi.org/10.1007/ s40725-019-00094-3

Kankare V, Holopainen M, Vastaranta M, Puttonen E, Yu XW, Hyyppä J, Vaaja M, Hyyppä H, Alho P (2013) Individual tree biomass estimation using terrestrial laser scanning. ISPRS J Photogramm 75:64-75. https://doi.org/10.1016/j.isprsjprs.2012.10.003

Kershaw JA Jr, Ducey MJ, Beers TW, Husch B (2016) Forest mensuration. Wiley, p 630

Koeser AK, Roberts JW, Miesbauer JW, Lopes AB, Kling GJ, Lo M, Morgenroth J (2016) Testing the accuracy of imaging software for measuring tree root volumes. Urban For Urban Gree 18:95-99. https://doi.org/10.1016/j.ufug.2016.05.009

Liang XL, Jaakkola A, Wang YS, Hyyppä J, Honkavaara E, Liu JB, Kaartinen H (2014) The use of a hand-held camera for individual tree 3D mapping in forest sample plots. Remote Sens-Basel 6(7):6587-6603. https://doi.org/10.3390/rs6076587

Liang XL, Kankare V, Hyyppä J, Wang YS, Kukko A, Haggrén H, Yu XW, Kaartinen H, Jaakkola A, Guan FY, Holopainen M, Vastaranta M (2016) Terrestrial laser scanning in forest inventories. ISPRS J Photogramm 115:63-77. https://doi.org/10.1016/j.isprs jprs.2016.01.006

Liang XL, Wang YS, Jaakkola A, Kukko A, Kaartinen H, Hyyppä J, Honkavaara E, Liu JB (2015) Forest data collection using terrestrial image-based point clouds from a handheld camera compared to terrestrial and personal laser scanning. IEEE T Geosci Remote 53(9):5117-5132. https://doi.org/10.1109/TGRS.2015.2417316

Liu JC, Feng ZK, Yang LY, Mannan A, Khan TU, Zhao ZY, Cheng ZX (2018) Extraction of sample plot parameters from 3D point cloud reconstruction based on combined RTK andCCD continuous photography. Remote Sens-Basel 10(8):1299. https://doi.org/ 10.3390/rs10081299

Marzulli MI, Raumonen P, Greco R, Persia M, Tartarino P (2020) Estimating tree stem diameters and volume from smartphone photogrammetric point clouds. Forestry. https://doi.org/10.1093/ forestry/cpz067
Miller J, Morgenroth J, Gomez C (2015) 3D modelling of individual trees using a handheld camera: accuracy of height, diameter and volume estimates. Urban For Urban Gree 14(4):932-940. https:// doi.org/10.1016/j.ufug.2015.09.001

Mokroš M, Liang XL, Surový P, Valent P, Čerňava J, Chudý F, Tunák D, Saloň Š, Merganič J (2018) Evaluation of close-range photogrammetry image collection methods for estimating tree diameters. ISPRS Int Geo-Inf 7(3):93. https://doi.org/10.3390/ijgi7 030093

Morgenroth J, Gómez C (2014) Assessment of tree structure using a 3D image analysis technique-a proof of concept. Urban For Urban Gree 13(1):198-203. https://doi.org/10.1016/j.ufug.2013.10.005

Mulverhill C, Coops NC, Tompalski P, Bater CW, Dick AR (2019) The utility of terrestrial photogrammetry for assessment of tree volume and taper in boreal mixedwood forests. Ann For Sci 76(3):83. https://doi.org/10.1007/s13595-019-0852-9

Özçelik R, Wiant HV Jr, Brooks JR (2008) Accuracy using xylometry of log volume estimates for two tree species in Turkey. Scand J Forest Res 23(3):272-277. https://doi.org/10.1080/0282758080 1995323

Panagiotidis D, Surový P, Kuželka K (2016) Accuracy of structure from motion models in comparison with terrestrial laser scanner for the analysis of $\mathrm{DBH}$ and height influence on error behaviour. J For Sci 62(8):357-365. https://doi.org/10.17221/92/2015-JFS

Piermattei L, Karel W, Wang D, Wieser M, Mokroš M, Surový P, Koreň M, Tomaštík J, Pfeifer N, Hollaus M (2019) Terrestrial structure from motion photogrammetry for deriving forest inventory data. Remote Sens-Basel 11(8):950. https://doi.org/10.3390/ rs 11080950

Projet B (2009) Exécution d'un Inventaire Forestier National: méthodologie et résultats d'inventaire au niveau national; système de suivi et évaluation. Bénin, DGFRN

R Core Team (2017) R: A language and environment for statistical computing. R foundation for statistical computing, Vienna, Austria. URL https://www.R-project.org/

Roberts J, Koeser A, Abd-Elrahman A, Wilkinson B, Hansen G, Landry S, Perez A (2019) Mobile terrestrial photogrammetry for street tree mapping anmeasurements. Forests 10(8):701. https:// doi.org/10.3390/f10080701

Rondeux J (1999) La mesure des arbres et des peuplements forestiers. Les presses agronomiques de Gembloux. p 522. http://hdl.handle. net $/ 2268 / 108388$

Saarinen N, Kankare V, Vastaranta M, Luoma V, Pyörälä J, Tanhuanpää T, Liang XL, Kaartinen H, Kukko A, Jaakkola A, Yu XW, Holopainen M, Hyyppä J (2017) Feasibility of Terrestrial laser scanning for collecting stem volume information from single trees. ISPRS Photogramm 123:140-158. https://doi.org/10.1016/j.isprs jprs.2016.11.012

Torgo L, Torgo ML (2013) Package 'DMwR'. Comprehensive R archive network

West PW (2015) Tree and forest measurement. Springer. https://doi. org/10.1007/978-3-319-14708-6,214p

Yu XW, Liang XL, Hyyppä J, Kankare V, Vastaranta M, Holopainen M (2013) Stem biomass estimation based on stem reconstruction from terrestrial laser scanning point clouds. Remote Sens Lett 4(4):344-353. https://doi.org/10.1080/2150704X.2012.734931

Publisher's Note Springer Nature remains neutral with regard to jurisdictional claims in published maps and institutional affiliations. 